\title{
Neighborhoods and Cognitive Aging: Effect of Cognitive Segregation?
}

\author{
Steven M. Albert \\ Department of Behavioral and Community Health Sciences, Graduate School of Public Health, \\ University of Pittsburgh, Pittsburgh, Pa., USA
}

In their study of older adults in Singapore, Wee et al. [1] showed that older adults residing in low-income housing score lower on an adapted Mini-Mental State Examination (MMSE) than more affluent neighbors. Older adults who rent residences score, on average, about 1 point lower than seniors who own apartments. Renters were nearly twice as likely to score below 24, the standard cut-off score for clinically significant impairment. The effect of poorer neighborhood persisted in models that adjusted for patient demographic and clinical features. Most notably, the neighborhood effect was not eliminated when models included adjustment for individual socioeconomic status, such as income and employment. As the authors write, 'After adjustment for individual SES, other clinical factors, and demographic factors (including age, gender, educational level, and ethnicity), elderly living in the low area SES communities were more likely to have cognitive impairment (adjusted OR 5.13, 95\% CI $1.98-13.34, \mathrm{p}=0.001$ ) compared to their counterparts in owner-occupied blocks'.

The potency of neighborhood for cognitive status appears especially striking for these Chinese, Malay, and Tamil seniors. Ownership of a residence is undoubtedly correlated with employment, poverty, government income supports, education, and many other current and lifetime indicators of socioeconomic status. Yet it is notable that these Singapore neighborhood blocks are adjacent (indeed, they were chosen for this reason). These people live in the same 'place' but differ in socioeconomic status. This is an important feature of the study design. While this study joins many others demonstrating a similar neighborhood effect for cognitive status [2-7], the other studies compare communities that differ widely in many features, ranging from access to care to physical environments. The Singapore study offers control over variation in these features of communities. 
Thus, physically proximate neighbors can have a very different experience of cognitive aging. The authors reason that this difference is due to differences in social proximity. According to their observations (not, however, measured in the study), the housing blocks are quite segregated. Social interaction is limited across low- and high-income neighborhoods. The authors go on to say, 'Residents of poor neighborhoods, regardless of their own class, are likely to have interaction with neighbors who, because of disadvantage, may be unable to offer extensive cognitive stimulation, constrained by limited education and financial stress, whereas residents in more affluent neighborhoods are exposed to neighbors who can provide more extensive cognitive stimulation'. While still in need of research to demonstrate these claims, this suggests an important mechanism for the cognitive effect of place. The independent effect for neighborhood or community may involve social networks and cognitive aspects of daily social interaction.

How would one investigate this mechanism? Older adults in the two neighborhoods would need to be tracked for daily interaction. This would give an indication of segregation. If evident, we would then need to know the extent to which social segregation results in what we might call cognitive segregation. Does greater contact with people of higher socioeconomic status result in greater cognitive stimulation? How so? Does it matter if contact occurs in the high- or low-socioeconomic neighborhood? How segregated do the neighborhoods have to be to produce the differences in cognitive performance seen in this observational study? How much of a gain in cognitive performance from daily interaction is plausible to produce these kinds of differences?

I have argued elsewhere [8] that one way to capture these dynamic properties is to use agent-based computational models to 'grow' phenomena of interest [9]. Agent-based simulations, increasingly important for infectious disease modeling, may help us understand the effects of place on health. In such models, we would need to simulate the interaction of agents across different neighborhoods and develop rules for incrementing cognitive performance resulting from such interaction. Can we grow differences as large as those observed in Singapore? How much of a gain in cognitive performance from daily interaction is required? How much contact must individuals in different neighborhoods have? By forcing such specificity, we commit to testing mechanisms of community effect.

Wee et al. [1] raise this segregation effect as a potential explanation for neighborhood differences in MMSE performance. Other explanations include lifelong cognitive effects of low education and low income, which have been increasingly identified as sources of poor cognitive function in later life $[10,11]$. An important task for future research will be to try to disentangle the effects of place and lifelong risk factors that affect residential options. Whatever the mechanism, this study again provides support for social factors in vulnerability to cognitive decline.

\section{References}

1 Wee LE, Yeo WX, Yang GR, Hannan N, Lim K, Chua C, Tan MY, Fong N, Yeap A, Chen L, Koh GCH, Shen HM: Individual and area level socioeconomic status and its association with cognitive function and cognitive impairment (low MMSE) among community-dwelling elderly in Singapore. Dement Geriatr Cogn Disord Extra 2012;2:529-542.

2 Basta NE, Matthews FE, Chatfield MD, Brayne C: Community-level socio-economic status and cognitive and functional impairment in the older population. Eur J Public Health 2008; 18:48-54.

3 Lang IA, Llewellyn DJ, Langa KM, Wallace RB, Huppert FA, Melzer D: Neighborhood deprivation, individual socioeconomic status, and cognitive function in older people: analyses from the English Longitudinal Study of Ageing. J Am Geriatr Soc 2008;56:191-198. 
-4 Sheffield KM, Peek MK: Neighborhood context and cognitive decline in older Mexican Americans: results from the Hispanic Established Populations for Epidemiologic Studies of the Elderly. Am J Epidemiol 2009;169:1092-1101.

-5 Aneshensel CS, Ko MJ, Chodosh J, Wight RG: The urban neighborhood and cognitive functioning in late middle age. J Health Soc Behav 2011;52:163-179.

-6 Zeki Al Hazzouri A, Haan MN, Osypuk T, Abdou C, Hinton L, Aiello AE: Neighborhood socioeconomic context and cognitive decline among older Mexican Americans: results from the Sacramento Area Latino Study on Aging. Am J Epidemiol 2011;174:423-431.

-7 Shih RA, Ghosh-Dastidar B, Margolis KL, Slaughter ME, Jewell A, Bird CE, Eibner C, Denburg NL, Ockene J, Messina CR, Espeland MA: Neighborhood socioeconomic status and cognitive function in women. Am J Public Health 2011;101:1721-1728.

8 Albert SM: Time to specify mechanisms of community health benefit or harm. Prev Med 2012, E-pub ahead of print.

9 Epstein JS: Generative Social Science: Studies in Agent-Based Computational Modeling. Princeton, Princeton University Press, 2006.

10 Smyth KA, Fritsch T, Cook TB, McClendon MJ, Santillan CE, Friedland RP: Worker functions and traits associated with occupations and the development of AD. Neurology 2004;63:498-503.

11 Piccinin AM, Muniz-Terrera G, Clouston S, Reynolds CA, Thorvaldsson V, Deary IJ, Deeg DJ, Johansson B, Mackinnon A, Spiro A 3rd, Starr JM, Skoog I, Hofer SM: Coordinated analysis of age, sex, and education effects on change in MMSE scores. J Gerontol B Psychol Sci Soc Sci 2012, E-pub ahead of print. 